Check for updates

Cite this: RSC Adv., 2021, 11, 29797

Received 17th July 2021

Accepted 25th August 2021

DOI: 10.1039/d1ra05492a

rsc.li/rsc-advances

\section{Simultaneous determination of Avanafil and Dapoxetine in human plasma using liquid chromatography/tandem mass spectrometry (LC- MS/MS) based on a protein precipitation technique}

\begin{abstract}
Mona N. Abou-Omar, ${ }^{a}$ Abdelaziz M. Annadi, ${ }^{b}$ Noha M. El Zahar, ${ }^{c d}$ Ahmed. O. Youssef, ${ }^{b}$ Mohammed A. Amin, (D) Mohamed S. Attia (D) ${ }^{* b}$ and Ekram H. Mohamed ${ }^{f}$

A rapid and selective LC-MS/MS method is described for the simultaneous assay of Avanafil and Dapoxetine in human plasma via a protein precipitation (PP) sample preparation technique. Tadalafil was chosen as the internal standard reaching good recovery and reproducibility while diminishing the effects of the matrix. An Agilent Zorbax Eclipse XDB $C_{18}$ column $(4.6 \times 50 \mathrm{~mm}, 1.8 \mu \mathrm{m})$ was used for the chromatographic separation and analysis, while $0.1 \%$ formic acid : acetonitrile $(60: 40, \mathrm{v} / \mathrm{v})$ was utilized at a flow rate of $0.5 \mathrm{~mL} \mathrm{~min}{ }^{-1}$. It was revealed that $6 \mathrm{~min}$ stop time accomplished the best separation. The assay was linear over the range of 10-6000 $\mathrm{ng} \mathrm{mL}^{-1}$ for both drugs. The established bio-analytical method validation was demonstrated following US-FDA recommendations including sensitivity, selectivity, linearity, accuracy and precision. Furthermore, other validation parameters were assessed such as the dilution integrity, matrix effect, carryover, and analyte stability during both short- and long-term sample processing and storage. The adopted method was efficaciously applied to a clinical study for the concurrent determination of Avanafil and Dapoxetine in human plasma.
\end{abstract}

\section{Introduction}

Avanafil, (S)-4-((3-chloro-4-methoxybenzyl)amino)-2-(2-(hydroxymethyl)pyrrolidin-1-yl)- $N$-(pyrimidin-2-ylmethyl)pyrimidine-5carboxamide (Fig. 1a), is a phosphodiesterase type 5 inhibitor with an efficient vasodilation effect. It has been widely used in the treatment of erectile dysfunction and impotence. Moreover, Avanafil action has been investigated for the treatment of pulmonary hypertension. ${ }^{1}$ Dapoxetine, $(S)-N, N$-dimethyl-3(naphthalene-1-yloxy)-1-phenylpropan-1-amine (Fig. 1b), promotes the obstruction of the serotonin transporter, leading to the enhancement of the effect of serotonin at the postsynaptic cleft, thus, promoting the ejaculatory delay. ${ }^{2}$ Combining both drugs in a single dosage form for the treatment

${ }^{a}$ Department of Chemistry, Faculty of Women for Arts, Science and Education, Ain Shams University, Cairo, Egypt

${ }^{b}$ Chemistry Department, Faculty of Science, Ain Shams University, Abbassia, Cairo, 11566,Egypt.E-mail:mohd_mostafa@sci.asu.edu.eg; mohamed_sam@yahoo.com 'Pharmaceutical Analytical Chemistry Department, Faculty of Pharmacy, Ain Shams University, Organization of African Unity Street, Abassia, Cairo 11566, Egypt

${ }^{d}$ Medicinal Chemistry Department, Faculty of Pharmacy, King Salman International University, Ras-Sedr, South Sinai, Egypt

${ }^{e}$ Department of Chemistry, College of Science, Taif University, P.O. BOX 11099, Taif 21944, Saudi Arabia

${ }^{f}$ Pharmaceutical Chemistry Department, Faculty of Pharmacy, The British University in Egypt, 11837, El Sherouk City, Cairo, Egypt of erectile dysfunction was officially approved by the U.S. Food and Drug Administration (FDA) in April 2012. ${ }^{3}$

A literature survey revealed some analytical techniques for Avanafil and Dapoxetine determination either individually or in<smiles>COc1ccc(CNc2nc(N3CCC[C@H]3CO)ncc2C(=O)NCc2ncccn2)cc1Cl</smiles><smiles>CN(C)[C@H](CCOc1cccc2ccccc12)c1ccccc1</smiles>

Fig. 1 Structure of (a) Avanafil and (b) Dapoxetine. 
Table 1 A comparison between literature and the developed method regarding different LCMS/MS methods used for the determination of Avanafil and Dapoxetine

\begin{tabular}{|c|c|c|c|c|c|c|c|}
\hline Analytes & $\begin{array}{l}\text { Extraction } \\
\text { technique }\end{array}$ & Stationary phase & Mobile phase & $\begin{array}{l}\text { MRM ion transitions } m / z \\
\text { with MS detection }\end{array}$ & $\begin{array}{l}\text { Linear } \\
\text { range, } \\
\mathrm{ng} \\
\mathrm{mL}^{-1}\end{array}$ & Applications & Ref. \\
\hline Avanafil & $\begin{array}{l}\text { Solvent } \\
\text { extraction }\end{array}$ & $\begin{array}{l}\text { Chromolith }{ }^{\circledR} \mathrm{RP}^{-\mathrm{C}_{18^{-}}} \\
18 \mathrm{e},(4.6 \times 100 \mathrm{~mm})\end{array}$ & $\begin{array}{l}0.1 \% \text { formic acid in } \\
\text { water }: 0.1 \% \text { formic acid } \\
\text { in acetonitrile }(75: 25, \mathrm{v} / \\
\text { v) at a flow rate of } 0.5 \\
\mathrm{~mL} \mathrm{~min}^{-1}\end{array}$ & $\begin{array}{l}\text { Avanafil } 483.95 \rightarrow \\
(375.1,155.05,233.1)\end{array}$ & $\begin{array}{l}150- \\
6000\end{array}$ & $\begin{array}{l}\text { Pharmaceutical } \\
\text { preparations }\end{array}$ & 21 \\
\hline Avanafil & $\begin{array}{l}\text { Solid-phase } \\
\text { extraction }\end{array}$ & $\begin{array}{l}\text { Capcell Pak } \mathrm{C}_{18}(2.0 \times \\
50 \mathrm{~mm}, 3 \mu \mathrm{m})\end{array}$ & $\begin{array}{l}10 \mathrm{mM} \text { ammonium } \\
\text { formate, } \mathrm{pH} \\
2.5: \text { acetonitrile } \\
(65: 35, \mathrm{v} / \mathrm{v}), \text { at a flow } \\
\text { rate of } 0.3 \mathrm{~mL} \mathrm{~min} \mathrm{~min}^{-1}\end{array}$ & Avanafil $484.1 \rightarrow(375.1)$ & $1-250$ & Human plasma & 22 \\
\hline Avanafil & $\begin{array}{l}\text { Solvent } \\
\text { extraction }\end{array}$ & $\begin{array}{l}\text { Poroshell } 120 \mathrm{EC}^{-\mathrm{C}_{18}} \\
(3.0 \times 150 \mathrm{~mm}, 2.7 \mu \mathrm{m})\end{array}$ & $\begin{array}{l}10 \mathrm{mM} \text { ammonium } \\
\text { formate and formic acid, } \\
\mathrm{pH} 4.6 \text { in ultrapure } \\
\text { water }: 0.1 \% \text { formic acid } \\
\text { in acetonitrile at flow } \\
\text { rate of } 0.55 \mathrm{~mL} \mathrm{~min}^{-1}\end{array}$ & $\begin{array}{l}\text { Avanafil } 484.18566 \rightarrow \\
(375.1217,155.0254)\end{array}$ & $5-1000$ & Urine samples & 23 \\
\hline Dapoxetine & $\begin{array}{l}\text { Protein } \\
\text { precipitation }\end{array}$ & $\begin{array}{l}\text { Acquity BEH C } 18(2.0 \times \\
100 \mathrm{~mm}, 1.7 \mu \mathrm{m})\end{array}$ & $\begin{array}{l}\text { Acetonitrile }: 0.1 \% \\
\text { formic acid, pH } 6.0 \\
\text { adjusted with } \\
\text { ammonium hydroxide } \\
(45: 55, \mathrm{v} / \mathrm{v}), \text { at a flow } \\
\text { rate of } 0.2 \mathrm{~mL} \mathrm{~min}^{-1}\end{array}$ & $\begin{array}{l}\text { Dapoxetine } 306.2 \rightarrow \\
(261.1)\end{array}$ & $1-500$ & Rat plasma & 24 \\
\hline Dapoxetine & $\begin{array}{l}\text { Protein } \\
\text { precipitation }\end{array}$ & $\begin{array}{l}\mathrm{C}_{18} \text { Fortis }(2.0 \times 50 \mathrm{~mm} \text {, } \\
1.7 \mu \mathrm{m})\end{array}$ & 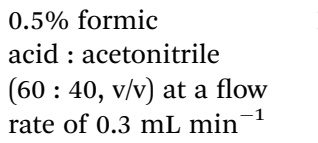 & Dapoxetine $306 \rightarrow(261)$ & $1-500$ & Rat plasma & 25 \\
\hline Dapoxetine & $\begin{array}{l}\text { Liquid-liquid } \\
\text { extraction }\end{array}$ & $\begin{array}{l}\text { ACE C } 8(4.6 \times 50 \mathrm{~mm}, \\
5.0 \mu \mathrm{m})\end{array}$ & $\begin{array}{l}\text { Acetonitrile }: 0.01 \mathrm{M} \\
\text { ammonium acetate }+ \\
0.02 \% \text { formic acid } \\
\text { solution }(85: 15, \mathrm{v} / \mathrm{v}) \text { at } \\
\text { a flow rate of } 0.9 \\
\mathrm{~mL} \min ^{-1}\end{array}$ & $\begin{array}{l}\text { Dapoxetine } 306.2 \rightarrow \\
(157.2)\end{array}$ & $5.0-600$ & Human plasma & 26 \\
\hline Dapoxetine & $\begin{array}{l}\text { Protein } \\
\text { precipitation }\end{array}$ & $\begin{array}{l}\text { Ultimate } \mathrm{XB} \mathrm{C}_{18},(2.1 \times \\
50 \mathrm{~mm}, 5.0 \mu \mathrm{m})\end{array}$ & $\begin{array}{l}0.1 \% \text { formic } \\
\text { acid : acetonitrile } \\
\text { containing } 0.1 \% \text { formic } \\
\text { acid at a flow rate of } 0.8 \\
\mathrm{~mL} \min ^{-1}\end{array}$ & $\begin{array}{l}\text { Dapoxetine } 306.2 \rightarrow \\
(157.2)\end{array}$ & $1-500$ & Human plasma & 27 \\
\hline Dapoxetine & $\begin{array}{l}\text { Protein } \\
\text { precipitation }\end{array}$ & $\begin{array}{l}\text { Acquity UPLC BEH C }{ }_{18} \\
(2.1 \mathrm{~mm} \times 50 \mathrm{~mm}, 1.7 \\
\mu \mathrm{m})\end{array}$ & $\begin{array}{l}\text { Acetonitrile }: 0.1 \% \\
\text { formic acid at a flow rate } \\
\text { of } 0.4 \mathrm{~mL} \mathrm{~min} \\
-1\end{array}$ & $\begin{array}{l}\text { Dapoxetine } 306.3 \rightarrow \\
(261.2)\end{array}$ & - & Rat plasma & 28 \\
\hline $\begin{array}{l}\text { Avanafil, } \\
\text { Dapoxetine }\end{array}$ & $\begin{array}{l}\text { Protein } \\
\text { precipitation }\end{array}$ & $\begin{array}{l}\text { Zorbax eclipse XDB } \mathrm{C}_{18} \\
(4.6 \times 50 \mathrm{~mm}, 1.8 \mu \mathrm{m})\end{array}$ & $\begin{array}{l}0.1 \% \text { formic } \\
\text { acid : acetonitrile } \\
(60: 40, \mathrm{v} / \mathrm{v}) \text { at a flow } \\
\text { rate of } 0.5 \mathrm{~mL} \mathrm{~min} \mathrm{~mL}^{-1}\end{array}$ & $\begin{array}{l}\text { Avanafil } 485 \rightarrow(375, \\
\text { 155), Dapoxetine } 306 \rightarrow \\
(183,157)\end{array}$ & $\begin{array}{l}10- \\
6000\end{array}$ & Human plasma & $\begin{array}{l}\text { The } \\
\text { developed } \\
\text { method }\end{array}$ \\
\hline
\end{tabular}

conjunction with other medicines. These techniques included UV spectrophotometry, ${ }^{\mathbf{1 , 2 , 4 - 1 0}}$ spectrofluorimetry ${ }^{\mathbf{6 , 1 1 - 1 6}}$ and capillary electrophoresis. ${ }^{\mathbf{1 7}}$ Various chromatographic methods were also applied for determination of the cited mixture such as HPTLC $^{4}$ and HPLC with different detectors as UV, fluorescence detection $^{\mathbf{1 , 8 , 9 , 1 2 , 1 6 , 1 8 - 2 0}}$ and with tandem mass spectrometry. ${ }^{21-28} \mathrm{~A}$ brief comparison between the different LC-MS/MS methods from the previously reported in the literature and the developed one is elucidated in Table 1.
To the best of our knowledge, in spite of the extensive methods previously applied for the analysis of Avanafil and Dapoxetine, there is no LC-MS/MS method for simultaneous determination of both analytes under investigation in human plasma matrix applying Protein Precipitation (PP) technique for sample preparation while using Tadalafil as an internal standard (IS).

Thus, our aim was to establish a selective and sensitive LCMS/MS method applying a cost effective procedures for sample preparation in order to avoid matrix effect and charge 

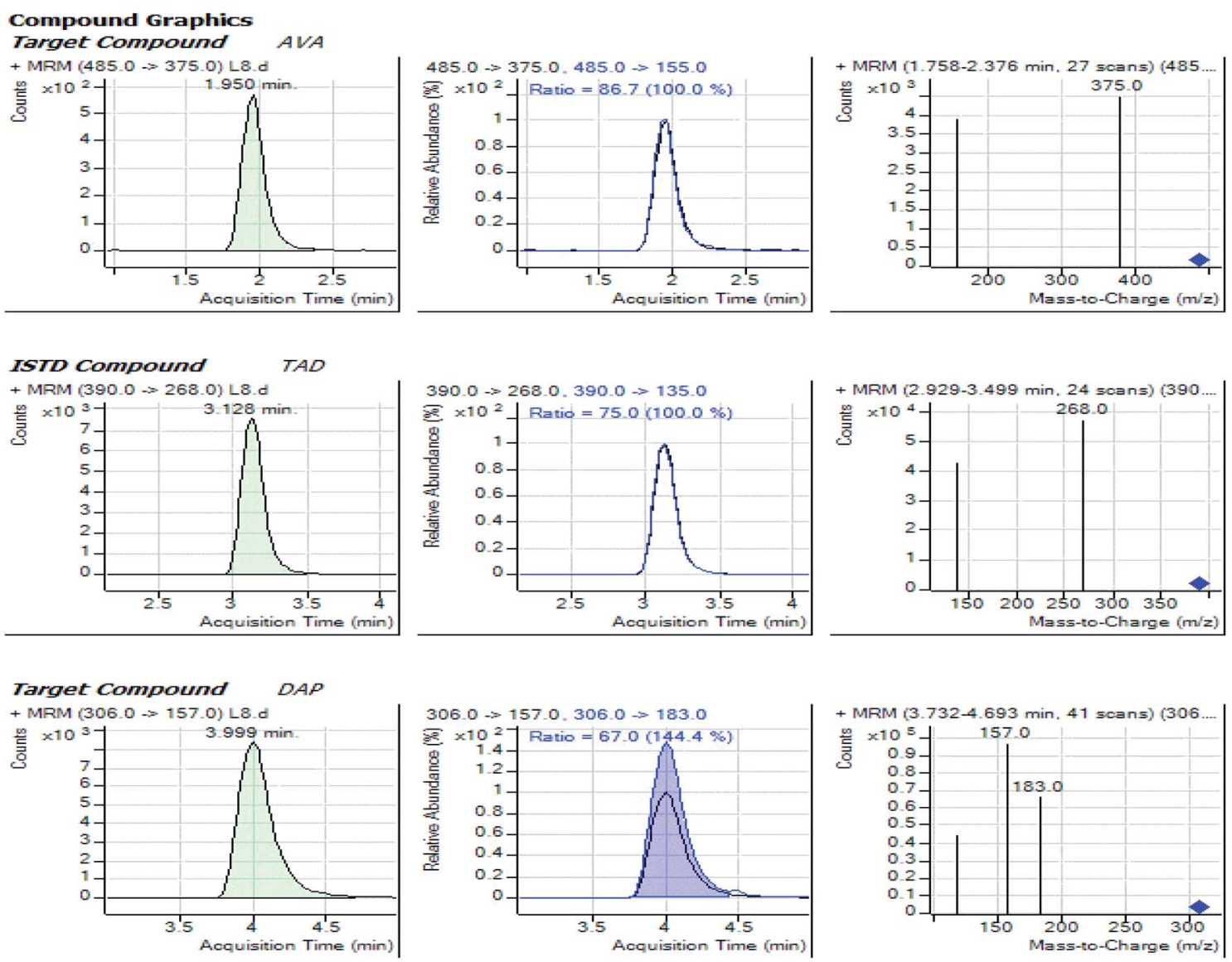

Fig. 2 Chromatograms of Avanafil, Dapoxetine and Tadalafil.

competition troublesome which represent serious challenges in face of LC-MS/MS method development. Furthermore, the adopted method has been verified and validated following the US-FDA guidelines. The suggested method exhibited important advantages, comprising the shorter run time, wider linearity range and the enhanced sensitivity, accuracy and precision.

\section{Materials and reagents}

Avanafil, purity (99.95\%), was acquired from Rakshit Drugs Pvt. Ltd., Hyderabad, India. Dapoxetine $\mathrm{HCl}$, purity (99.97\%), was acquired from Synergene Active Ingredients Pvt. Ltd., Hyderabad, India. Tadalafil, purity (99.96\%), was acquired from Amoli Organics Pvt. Ltd., Mumbai, India. Ultrapure water ASTM grade I was regularly prepared. Other chemicals comprising HPLC grade solvents, formic acid, acetonitrile, ethyl acetate, and methanol were obtained from Sigma-Aldrich, St. Louis, MO, USA.

\subsection{Apparatus}

The LC-MS/MS assay was conducted via Agilent 6460 liquid chromatography coupled with triple quad mass spectrometer (LC-QqQ-MS) (Agilent Technologies, USA), the ion polarity was set in positive mode and Mass Hunter software (version B.03.01, Build 3.1.346.0).

\subsection{Chromatographic conditions}

The analytes were separated on the Agilent Zorbax Eclipse XDB $\mathrm{C}_{18}(4.6 \times 50 \mathrm{~mm}, 1.8 \mu \mathrm{m})$ column with controlled temperature at $25{ }^{\circ} \mathrm{C}$ and an isocratic mobile phase of $0.1 \%$ formic acid: acetonitrile in ratio of $(60: 40, v / v)$. An aliquot of $5 \mu \mathrm{L}$ was

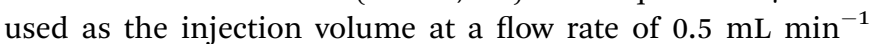
using Tadalafil as the IS.

\subsection{Mass spectrometric conditions}

The MS settings were implemented as the followings: Q1 precursor ions (485, 306 and 390); Q3 quantifying product ions $(375,183$ and 268) and Q3 qualifying product ions $(155,157$ and 135) for Avanafil, Dapoxetine and Tadalafil (IS); respectively. The fragmentation voltage was $135 \mathrm{~V}$ for all analytes while the collision energies were 28, 20 and $25 \mathrm{~V}$, for Avanafil, Dapoxetine and Tadalafil (IS); respectively. Polarity was set in electrospray ionization (ESI) positive mode with time filter width equal to $0.07 \mathrm{~min}$. Further MS parameters were costumed including $300{ }^{\circ} \mathrm{C}$ desolvation gas temperature, $6 \mathrm{~L} \mathrm{~min}^{-1}$ gas flow rate, 15 psi nebulizer and $4000 \mathrm{~V}$ capillary voltage.

\subsection{Sample preparation and extraction procedures}

2.4.1. Preparation of standard solutions. Avanafil $(500 \mu \mathrm{g}$ $\left.\mathrm{mL}^{-1}\right)$, Dapoxetine $\left(500 \mu \mathrm{g} \mathrm{mL}{ }^{-1}\right)$ and IS, Tadalafil, $\left(25 \mu \mathrm{g} \mathrm{mL} L^{-1}\right)$ 

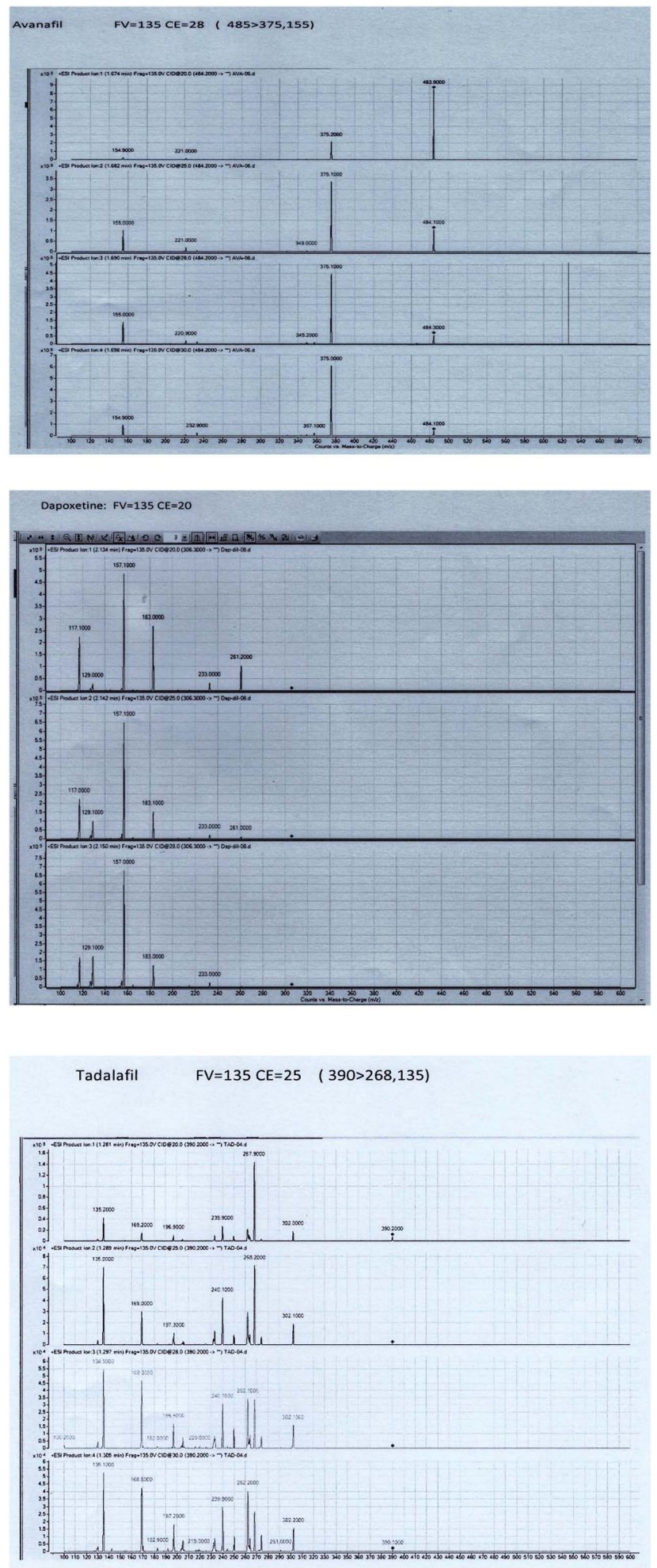

Fig. 3 Mass spectrum for (a) Avanafil, (b) Dapoxetine and (c) Tadalafil.

standard solutions were separately prepared in $100 \%$ methanol. Working standard solutions were adequately prepared by an appropriate dilution from their primary stock solutions to prepare the calibration standards and quality control (QC) samples. All solutions were maintained in freezer at $-20{ }^{\circ} \mathrm{C}$ once not in use.

2.4.2. Spiked human plasma sample preparation. Aliquots of the prepared working solutions were used to spike blank human plasma to prepare calibration standards and QC samples $\left(10,30,1500,5000 \mathrm{ng} \mathrm{mL}^{-1}\right)$. Sample preparation was implemented using a one-step PP extraction technique. A 100 $\mu \mathrm{L}$ from Tadalafil (IS) standard solution $\left(25 \mu \mathrm{g} \mathrm{mL} \mathrm{m}^{-1}\right)$ was added to an aliquot of $250 \mu \mathrm{L}$ plasma, vortexed for $2 \mathrm{~min}$., then $500 \mu \mathrm{L}$ acetonitrile was further added for the PP extraction. The prepared mixture was vortexed for $2 \mathrm{~min}$ and centrifuged at $6000 \mathrm{rpm}$ for $10 \mathrm{~min}$ followed by decantation. A $200 \mu \mathrm{L}$ was taken from the clear supernatant layer and a $5 \mu \mathrm{L}$ was injected into the column. The obtained results were interpreted as reported peak areas ratios to IS. Unknown concentrations of Avanafil and Dapoxetine samples were computed by referring to the plotted calibration curves (i.e. from computed regression equations).

\subsection{Bio-analytical method validation characteristics}

The adopted method was validated as per the US-FDA guidelines and guidance from the EMA. ${ }^{3,29}$ The method was validated for selectivity, sensitivity, linearity, accuracy, precision and carryover in the matrix. The dilution integrity, matrix effect, and analyte stability during both short and long-term sample processing and storage were also investigated.

2.5.1. Selectivity. Various sets of blank human plasma from various sources $(n=6)$ were investigated for checking the matrix interference by defining analyte chromatograms in blank plasma and analyte chromatograms at the LLOQ (10 ng $\mathrm{mL}^{-1}$ ). Injection of high concentrations directly after the blank samples was done to ensure the absence of a suggestive carry over.

2.5.2. Linearity and sensitivity. The linearity was assessed through measuring nine concentrations as calibration standard samples ranging from $10-6000 \mathrm{ng} \mathrm{mL}^{-1}$ in human plasma for both analytes. The calibration curves were plotted using the peak areas ratios of the analytes to IS.

2.5.3. Accuracy and precision. The accuracy $(n=6)$ was measured as recovery percent $(R \%)$ while intra-day $(n=6)$ and inter-day precision $(n=18)$, were measured as $(\mathrm{CV} \%)$ at the QC levels 10, 30, 1500 and $5000 \mathrm{ng} \mathrm{mL}^{-1}$.

2.5.4. Absolute recovery and matrix effect. The absolute recovery was measured through comparing the mean peak areas of Avanafil and Dapoxetine spiked human plasma samples at three QC levels, low QC (LQC), medium QC (MQC) and high QC (HQC), with those of the analytes in neat solvent at same concentrations. Furthermore, the matrix effect was assessed by comparing the mean peak areas of Avanafil and Dapoxetine post-preparation spiked human plasma samples with those of the analytes in neat solvent. The variability for both drugs was computed and expressed as (RSD\%).

2.5.5. Stability. The stability was investigated at LQC (10 ng $\left.\mathrm{mL}^{-1}\right)$ and HQC (5000 $\mathrm{ng} \mathrm{mL}^{-1}$ ) samples through the comparison of the freshly prepared spiked human samples and the samples exposed to the various stability conditions. The short 


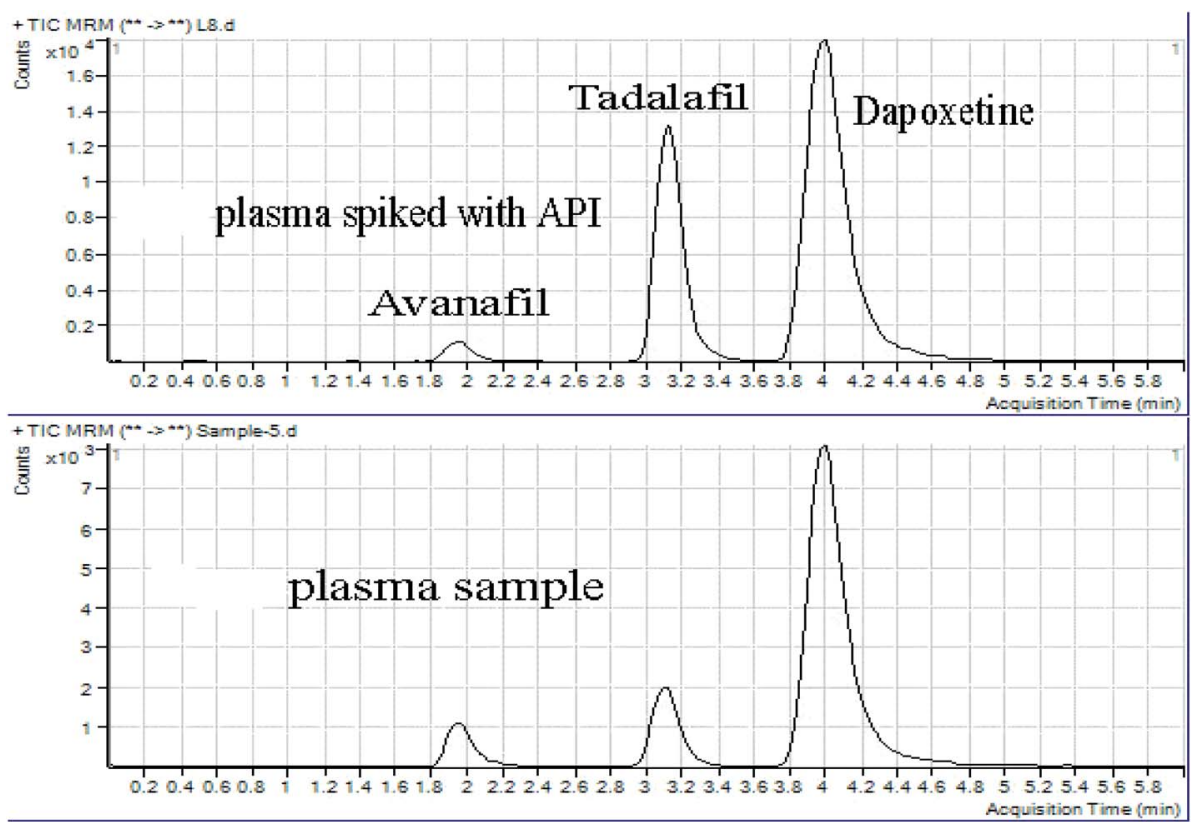

Fig. 4 Chromatograms of (a) human plasma spiked with (Avanafil \& Dapoxetine) standard \& Tadalafil (IS), and (b) human plasma sample from real subjects after 2 hours.

Table 2 Calibration curves for Avanafil and Dapoxetine analytes in human plasma

\begin{tabular}{lll}
\hline Parameters & Avanafil & Dapoxetine \\
\hline Linear range & $10-6000 \mathrm{ng} \mathrm{mL}$ & $10-6000 \mathrm{ng} \mathrm{mL}^{-1}$ \\
Linearity equation & $y=0.000030 x+$ & $y=0.000539 x-$ \\
& 0.000081 & 0.000462 \\
Slope & 0.000030 & 0.000539 \\
Intercept & +0.000081 & -0.000462 \\
$R^{2}$ & 0.998156 & 0.999680
\end{tabular}

term stability was assessed at $2-8{ }^{\circ} \mathrm{C}$ over $6-12 \mathrm{~h}$ and also after leaving the sample in the autosampler over $18-24 \mathrm{~h}$ at $2-8{ }^{\circ} \mathrm{C}$. The freeze and thaw stability was evaluated by means of three cycles at $-80{ }^{\circ} \mathrm{C}$. The long term stability was evaluated by checking the samples after two weeks while freezing at $-80{ }^{\circ} \mathrm{C}$.

2.5.6. Dilution integrity. The dilution integrity test was accomplished through diluting the spiked plasma to the upper

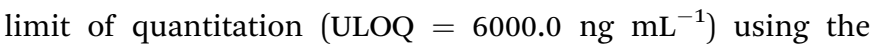
equivalent human blank plasma matrix to accommodate real samples with concentrations of the analytes above the ULOQ. The precision and accuracy of a 2 and 4-fold dilution were calculated.

\subsection{Real samples and ethical approval}

After the approval of the local ethical committee, $5 \mathrm{~mL}$ of blood samples from six volunteers were collected $2 \mathrm{~h}$ subsequent to the oral administration of the drug (Avanafil/Dapoxetine tablets; $200 / 60 \mathrm{mg}$ ). Then, centrifugation at $4000 \mathrm{rpm}$ was performed to extract the plasma. The plasma was removed, placed in aliquots, then frozen and stored at $-80{ }^{\circ} \mathrm{C}$. Ultimately, the extraction procedures were completed using the previously mentioned procedure under Section 2.5.2.

\section{Results and discussion}

The presented study aims are to investigate, develop and verify a simple and an effectively sensitive method with a short run-

Table 3 Avanafil and Dapoxetine analytes' precisions of in human plasma by means of the adopted PP method

\begin{tabular}{|c|c|c|c|c|c|c|c|c|c|}
\hline & \multicolumn{5}{|l|}{ Avanafil } & \multicolumn{4}{|c|}{ Dapoxetine } \\
\hline & QCs & LLOQ & LQC & MQC & HQC & LLOQ & LQC & MQC & HQC \\
\hline \multirow[t]{2}{*}{ Intraday precision } & Average (ng mL $\left.{ }^{-1}\right)$ & 10 & 26 & 1635 & 5034 & 9 & 33 & 1608 & 4956 \\
\hline & $\mathrm{CV} \%$ & 13.89 & 6.55 & 0.52 & 0.19 & 10.24 & 5.93 & 3.38 & 0.51 \\
\hline & $\mathrm{CV} \%$ & 14.21 & 12.48 & 3.11 & 9.03 & 13.65 & 10.46 & 3.41 & 1.16 \\
\hline & Accuracy $R \%$ & 90 & 97 & 106 & 108 & 91 & 101 & 107 & 100 \\
\hline
\end{tabular}


Table 4 Matrix effect and recovery of Avanafil and Dapoxetine by means of the adopted PP method

\begin{tabular}{|c|c|c|c|c|}
\hline \multirow[b]{2}{*}{ QCs } & \multicolumn{2}{|c|}{ Net solution } & \multicolumn{2}{|c|}{ Processed plasma } \\
\hline & LQC & HQC & LQC & HQC \\
\hline Conc. $\left(\mathrm{ng} \mathrm{mL}^{-1}\right)$ & 30 & 5000 & 30 & 5000 \\
\hline \multicolumn{5}{|l|}{ Avanafil } \\
\hline Average (peak area) & 171 & 30276 & 164 & 28867 \\
\hline $\mathrm{RSD} \%$ & 0.94 & 2.90 & 1.32 & 2.79 \\
\hline Matrix effect & & & \multicolumn{2}{|c|}{$\begin{array}{l}\text { Normalization } \\
\text { factor }\end{array}$} \\
\hline LQC & 96 & & LQC & 97 \\
\hline HQC & 95 & & & \\
\hline \multicolumn{5}{|l|}{ Dapoxetine } \\
\hline Average (peak area) & 3139 & 473010 & 3042 & 469207 \\
\hline $\mathrm{RSD} \%$ & 0.87 & 0.08 & 1.75 & 1.15 \\
\hline Matrix effect & & & \multicolumn{2}{|c|}{$\begin{array}{l}\text { Normalization } \\
\text { factor }\end{array}$} \\
\hline LQC & 97 & & LQC & 98 \\
\hline HQC & 99 & & & \\
\hline \multicolumn{5}{|l|}{ Tadalafil IS } \\
\hline Average & 91164 & & 89997 & \\
\hline RSD\% & 0.83 & & 2.14 & \\
\hline \multicolumn{5}{|l|}{ Matrix effect } \\
\hline LQC & 99 & & & \\
\hline
\end{tabular}

time per sample for the quantitative assessment of Avanafil and Dapoxetine at therapeutic concentrations in routine samples.

\subsection{Optimization of chromatographic conditions}

Imperative parameters were evaluated for achieving better sensitivity and chromatographic separation of the analytes. During the chromatographic separation method development, the adjusted parameters annulled the problems arisen from the charge competition and matrix effect without affecting the sensitivity, accuracy and precision of the method. Different reverse phase columns, such as Inertsil $\mathrm{C}_{18}$, Agilent $\mathrm{C}_{18}$ and Eclipse Plus, were examined and the Agilent Zorbax Eclipse XDB $\mathrm{C}_{18}$ column delivered completely separated peaks with best peak shape. The separation was affected by the use of methanol and acetonitrile and by increasing their percentage up to $85 \% \mathrm{v} /$ v. Acetonitrile achieved better separation; it exhibits low viscosity and low absorption in the UV region. It enables better mass transfer and better solubility for Avanafil and Dapoxetine. ${ }^{\mathbf{2 1 , 2 8}}$ Moreover, the use of an ion-suppressing agent, such as acetic acid, ammonium formate or formic acid was tested at various concentrations where the $0.1 \%$ formic acid was found to achieve good resolution and also to increase the sensitivity of Avanafil and Dapoxetine. The $\mathrm{pH}$ was changed from 2.5 to 7 and

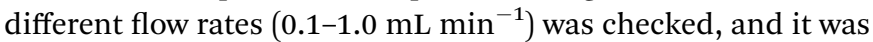
found that the $0.1 \%$ formic acid without the need for $\mathrm{pH}$ adjustment and the flow rate of $0.5 \mathrm{~mL} \mathrm{~min}{ }^{-1}$ provided a good resolution and peak shape and afforded a rapid analysis with shorter run time (6 $\mathrm{min})$.

Consequently, the chosen mobile phase was $0.1 \%$ formic acid : acetonitrile $(60: 40, \mathrm{v} / \mathrm{v})$ through an isocratic mode, at 0.5 $\mathrm{mL} \min ^{-1}$ as the flow rate while using the Agilent Zorbax Eclipse

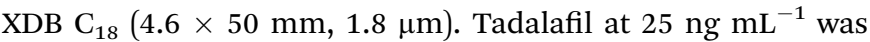
used as the IS. The adopted method delivered a proper chromatographic separation of the analytes with retention times of 1.95, 3.99 and 3.13 min. for Avanafil, Dapoxetine and Tadalafil IS; respectively, as indicated in Fig. 2. The developed method offered a considerable advantage for a great sample throughput necessary for the routine clinical analysis.

Table 5 Short term and autosampler stability of Avanafil and Dapoxetine by means of the adopted PP $\operatorname{method}^{a}$

\begin{tabular}{|c|c|c|c|c|c|c|c|}
\hline & QCs & \multicolumn{3}{|l|}{ LQC } & \multicolumn{3}{|l|}{ HQC } \\
\hline \multicolumn{8}{|c|}{ Short term stability } \\
\hline \multirow[t]{6}{*}{ Avanafil } & Conc. (ng $\mathrm{mL}^{-1}$ ) & 30 & & & 5000 & & \\
\hline & Sample no. & Initial & After $6 \mathrm{~h}$ & After $12 \mathrm{~h}$ & Initial & After $6 \mathrm{~h}$ & After $12 \mathrm{~h}$ \\
\hline & Average & 27 & 26 & 26 & 5144 & 5043 & 5204 \\
\hline & $\mathrm{RSD} \%$ & 7.62 & 9.56 & 7.69 & 1.83 & 1.03 & 1.51 \\
\hline & Accuracy $R \%$ & 91 & 88 & 87 & 103 & 101 & 104 \\
\hline & Stability\% & & 96 & 95 & & 98 & 101 \\
\hline \multirow[t]{4}{*}{ Dapoxetine } & Average & 31 & 31 & 29 & 5164 & 5096 & 4944 \\
\hline & $\mathrm{RSD} \%$ & 3.69 & 4.98 & 3.45 & 1.72 & 1.53 & 1.55 \\
\hline & Accuracy $R \%$ & 104 & 102 & 97 & 103 & 102 & 99 \\
\hline & Stability\% & & 98 & 93 & & 99 & 96 \\
\hline \multicolumn{8}{|c|}{ Autosampler stability } \\
\hline \multirow[t]{5}{*}{ Avanafil } & Sample no. & Initial & After $18 \mathrm{~h}$ & After $24 \mathrm{~h}$ & Initial & After $18 \mathrm{~h}$ & After $24 \mathrm{~h}$ \\
\hline & Average & 31 & 32 & 30 & 5422 & 5622 & 5511 \\
\hline & $\mathrm{RSD} \%$ & 4.88 & 4.82 & 3.33 & 1.97 & 3.40 & 3.43 \\
\hline & Accuracy $R \%$ & 104 & 106 & 100 & 108 & 112 & 110 \\
\hline & Stability\% & & 101 & 96 & & 104 & 102 \\
\hline \multirow[t]{4}{*}{ Dapoxetine } & Average & 34 & 31 & 30 & 5306 & 5134 & 5375 \\
\hline & $\mathrm{RSD} \%$ & 1.71 & 10.26 & 6.86 & 5.73 & 1.65 & 1.59 \\
\hline & Accuracy $R \%$ & 112 & 104 & 101 & 106 & 103 & 108 \\
\hline & Stability\% & & 93 & 90 & & 97 & 101 \\
\hline
\end{tabular}

${ }^{a}$ Three replicates from one homogenous Q.C sample. 
Table 6 Long term and freeze and thaw stability of Avanafil and Dapoxetine by means of the adopted PP method

\begin{tabular}{|c|c|c|c|c|c|c|c|}
\hline \multicolumn{2}{|c|}{ QCs } & \multicolumn{3}{|l|}{ LQC } & \multicolumn{3}{|l|}{ HQC } \\
\hline \multicolumn{8}{|c|}{ Long term stability } \\
\hline \multirow[t]{4}{*}{ Avanafil } & Conc. $\left(\mathrm{ng} \mathrm{mL}^{-1}\right)$ & 30 & & & 5000 & & \\
\hline & Average & 28 & 30 & 27 & 4870 & 5052 & 5030 \\
\hline & $\mathrm{RSD} \%$ & 7.14 & 7.02 & 7.41 & 7.69 & 3.34 & 7.27 \\
\hline & Accuracy\% & 93 & 99 & 90 & 97 & 101 & 101 \\
\hline & $\mathrm{RSD} \%$ & 7.95 & 8.48 & 4.98 & 7.13 & 3.61 & 5.50 \\
\hline & Accuracy $R \%$ & 106 & 99 & 102 & 104 & 101 & 95 \\
\hline & Stability $\%$ & & 94 & 97 & & 98 & 92 \\
\hline \multicolumn{8}{|c|}{ Freeze and thaw stability } \\
\hline Avanafil & Sample no. & Initial & 3rd cycle & & Initial & 3rd cycle & \\
\hline \multirow[t]{4}{*}{ Dapoxetine } & Average & 32.00 & 30.67 & & 5154.00 & 5428.33 & \\
\hline & $\mathrm{RSD} \%$ & 5.41 & 8.21 & & 1.00 & 2.24 & \\
\hline & Accuracy $R \%$ & 106.67 & 102.22 & & 103.08 & 108.57 & \\
\hline & Stability\% & & 96 & & & 105 & \\
\hline
\end{tabular}

\subsection{Optimization of MS parameters}

To obtain better specificity and reproducibility, MS was executed using ESI operated in the positive ion mode where the response for Avanafil, Dapoxetine and Tadalafil (IS) was considerably better than in negative ion mode. The detection of was conducted using the multiple-reaction-monitoring (MRM) mode achieving both high sensitivity and selectivity through using the utmost abundant fragment ions for each analyte. Solid and constant signals of both analytes and IS were denoted for the MRM ion transitions $m / z 485 \rightarrow(375,155), 306 \rightarrow(183$, $157)$ and $390 \rightarrow(268,135)$ for Avanafil, Dapoxetine and Tadalafil; respectively as illustrated in Fig. 3.

\subsection{Optimization of sample preparation}

In view of the polarities of both analytes Avanafil (XLogP3-AA = 2.6), Dapoxetine (XLogP3-AA = 5.1), and Tadalafil IS (XLogP3-AA $=2.3){ }^{30-32} \mathrm{PP}$ and liquid-liquid extraction (LLE) techniques using different solvents were investigated for testing the efficiency of the simultaneous extraction of both analytes and IS from human plasma. For LLE, several attempts were tested using ethyl acetate, diethyl ether and tertiary butyl ether as the extracting solvents, to achieve high extraction efficiency while minimizing the matrix effect and getting a substantial quantitative recovery. However, low and non-reproducible recovery were obtained (recovery \pm CV\%) $45 \pm 20 \%, 55 \pm 15 \%, 65 \pm$ $15 \%$; respectively. For PP technique, acetonitrile and methanol were investigated with different $\mathrm{v} / \mathrm{v} \%$. It was found that the PP method using acetonitrile was more suitable for the extraction of both analytes and IS based on the higher and better reproducible recovery as $90 \pm 7 \%$. Tadalafil IS was used to reach suitable precision and accuracy and to improve reproducibility while diminishing the matrix effect. Thus, the matrix effect became less prominent and the recovery remained directly associated to the method sensitivity".

\subsection{Selectivity}

Selectivity is well-defined as the capability of the chromatographic method to measure the response from Avanafil and Dapoxetine without any effect from the biological matrix. The selectivity was assessed using different sets of blank human plasma $(n=6)$. These samples were extracted, processed and analyzed following the adopted procedure. The results following applying the PP method on blank plasma while comparing to those from the spiked plasma samples at LLOQ $\left(10 \mathrm{ng} \mathrm{mL}^{-1}\right.$ ) displayed the lack of endogenous baseline interferences at the estimated retention times of Avanafil (1.95 min), Dapoxetine (3.99 $\mathrm{min}$ ), and Tadalafil IS (3.13 $\mathrm{min})$. This demonstrated the significant selectivity of the implemented assay of Avanafil and Dapoxetine in the presence of matrix components as illustrated in Fig. 4.

\subsection{Linearity and sensitivity}

The linearity was estimated using six replicates examination of a blank sample (treated plasma deprived of analytes or IS), a zero sample (treated plasma with only IS), and nine non zero samples (treated plasma samples containing both analytes and IS). Peak area ratios of analytes to the IS were constructed against their corresponding concentrations. The linearity was appraised by least-squares regression analysis and the calibration curves were shown to be linear $\left(R^{2}>0.998\right)$ within the ranges of 10-6000 $\mathrm{ng} \mathrm{mL}^{-1}$ for Avanafil and Dapoxetine analytes as shown in Table 2. The regression equations obtained from the mean calibration curves were: 


$$
\begin{gathered}
y=0.000030 x+0.000081 ; R^{2}=0.998156 \text { (for Avanafil), } \\
y=0.000539 x-0.000462 ; R^{2}=0.999680 \text { (for Dapoxetine), }
\end{gathered}
$$

$Y$ represents the peak area ratios to the IS (response) while $X$ represents the drug concentrations $\left(\mathrm{ng} \mathrm{mL} \mathrm{m}^{-1}\right)$.

Blank and zero samples were included in the regression examination in order to confirm the lack of interference. The accuracy $(\% R)$ of the calibration standards were in the range of (94 to 106\%), and (97 to $112 \%$ ), for Avanafil and Dapoxetine; respectively, as revealed in Table 3 . The method sensitivity denoted by the LLOQ (10 $\mathrm{ng} \mathrm{mL}^{-1}$ ) was estimated using six replicates assessments within $20 \%$ precision and accuracy and also by evaluating the analytes signal-to-noise ratio $(\mathrm{S} / \mathrm{N})$.

\subsection{Precision}

The intra-assay precision/repeatability is the extent of the within a day precision by means of the similar investigational variables with the same analyst in a short time period. ${ }^{3-42}$ While the inter-assay precision/reproducibility is the extent of the between days or between sets precision and may comprise several variables. Table 3 displays the intraday, analyst-toanalyst and the inter-day precision results needed for the evaluation of both analytes. The data are in accordance with the USFDA guidelines. The results revealed the high precision of the proposed method.

\subsection{Absolute recovery and matrix effect}

The absolute recovery was computed through using the peak area ratios among spiked samples and relating them to the mean peak area ratios of neat standard solutions with equivalent concentrations and was found to be $90 \pm 7 \%$ for both analytes. The matrix effect is the variation in signal response due to the occurrence of unintended analytes or interfering substances in the sample. The matrix effect is inspected in order to disclose potential ionization suppression or enhancement triggered by the matrix different components. Adequate recoveries for analytes indicated that the existing sample processing conditions efficaciously withdrawn matrix interference, as shown in Table 4 . The matrix effect was studied through the mean peak area ratios between the post-preparation spiked QC samples (LQC and HQC) compared to those acquired from the assessment of neat standards with same concentrations. Ion suppression was detected for both analytes, at all QC concentrations. Mean recovery percentages and \% RSD were in the acceptable range, as summarized in Table 4.

\subsection{Stability}

The short term stability is evaluated by comparing the peak areas of the samples which have been prepared and assessed immediately with those obtained after usual sample storage of 6 to $12 \mathrm{~h}$. Nevertheless, the long-term stability test is adopted to assess whether the analyte shows a proper stability in the biological matrices as the human plasma under the sample storage conditions during the time period necessary for the samples produced from a clinical analysis study to be examined (Table 5).

The sample stability was assessed throughout short term storage $\left(24 \mathrm{~h}\right.$ at $\left.2-8{ }^{\circ} \mathrm{C}\right)$. Besides, the samples were also evaluated after being stored in the autosampler (at 2-8 ${ }^{\circ} \mathrm{C}$ ) for $24 \mathrm{~h}$. The response achieved using the LC-MS/MS assay was matched to that of the freshly prepared solutions and proved an acceptable stability as shown in Table 4 .

The freeze and thaw stability test is performed to confirm that the sample exhibits an efficient stability after it is exposed to many freeze and thaw cycles within the study process. This can be accomplished by thawing the samples at LQC and HQC while allowing them to freeze again among 12 to $24 \mathrm{~h}$. The cycle is commonly repeated two times and the sample is analyzed and the results are compared constantly to that of the freshly prepared samples. In the adopted study, thawing of the Avanafil and Dapoxetine frozen samples and retaining them at room temperature for $24 \mathrm{~h}$ did not result in the analytes and IS degradation. The results illustrated in Table 6 confirmed that three cycles of freeze and thaw for the LQC and HQC samples did not disrupt both analytes quantification. The QC samples were kept frozen at $-80{ }^{\circ} \mathrm{C}$ and retained their stability for at least 14 days. Long term stability results are indicated in Table 6 revealing that the analysis of both analytes can be controlled under long term stability settings lacking any significant degradation for both analytes.

\subsection{Dilution integrity}

Dilution of the Avanafil and Dapoxetine samples should not interfere with the accuracy and precision. Dilution integrity can be verified by spiking the matrix with concentrations of the analyte over the ULOQ and then dilution of the samples with blank matrix. The set criteria for the accuracy and precision should be within $\pm 15 \%$. Dilution integrity should cover the practical dilution of the analyzed samples. The precision results (CV\%) for a 2 and 4 -fold dilution were within $3.1 \%$ and $4.7 \%$, while the accuracy results were within $98 \%$ and $102 \%$; respectively, acclaiming that a 2 and 4 -fold matrix matched dilution integrity are appropriate to preclinical samples with concentrations above the ULOQ.

\subsection{Application}

The maximum serum concentration is reached approximately 0.3-1.15 $\mathrm{h}$ and 1-2 $\mathrm{h}$ and after the oral administration of Avanafil and Dapoxetine; respectively. ${ }^{21-28}$ Hence, the validated bioanalytical method was efficiently applied to analyze Avanafil and Dapoxetine in human plasma from real subjects $2 \mathrm{~h}$ following the oral administration of (Avanafil/Dapoxetine tablets; 200/60 mg) showing (average concentrations $\pm \%$ $\mathrm{RSD})$ of (3000/250 $\left.\mathrm{ng} \mathrm{mL} \mathrm{mL}^{-1} \pm 5 \%\right)$, for Avanafil and Dapoxetine; respectively.

\section{Conclusions}

An appropriately fast and accurate LC-MS/MS assay was established and efficiently validated for the simultaneous 
determination of Avanafil and Dapoxetine in human plasma by means of a simple and effective PP method. The results of the validation study revealed that the implemented assay was selective, precise, accurate and reproducible over the concentration ranges $10-6000 \mathrm{ng} \mathrm{mL}^{-1}$ for both analytes. The adopted method exhibited an appropriate extraction recovery with lack of significant matrix interference. The suggested sample preparation protocol has been successfully applied to conserve the integrity of the studied drugs in bioequivalence studies.

\section{Funding sources}

This research did not receive any specific grant from funding agencies in the public, commercial, or not-for-profit sectors.

\section{Conflicts of interest}

There are no conflicts to declare.

\section{Acknowledgements}

Authors would like to acknowledge Taif University Researchers Supporting Project (2020/03), Taif University, Taif, Saudi Arabia, for providing full support to this work.

\section{References}

1 M. N. Patel and C. S. Kothari, Multivariate approaches for simultaneous determination of Avanafil and Dapoxetine by UV chemometrics and HPLC-QbD in binary mixtures and pharmaceutical product, J. AOAC Int., 2016, 99(3), 649-663.

2 M. A. Magdy, et al., Quantitative determination of Dapoxetine hydrochloride and Tadalafil using different validated spectrophotometric methods, Spectrochim. Acta Mol. Biomol. Spectrosc., 2020, 226, 117611.

3 G. Nicot, et al., Ion-pair extraction and high-performance liquid chromatography determination of tianeptine and its metabolites in human plasma, urine and tissues, $J$. Chromatogr., B, 1986, 381, 115-126.

4 I. A. Naguib, et al., A validated green HPTLC method for quantitative determination of Dapoxetine hydrochloride and Tadalafil in bulk and pharmaceutical formulations, $J$. Chromatogr. Sci., 2020, 58(4), 303-308.

5 G. Benkovics, et al., Single-isomer carboxymethyl-gammacyclodextrin as chiral resolving agent for capillary electrophoresis, J. Chromatogr., A, 2016, 1467, 445-453.

$6 \mathrm{H}$. S. Elama, et al., Validated spectrophotometric and spectrofluorimetric methods for determination of Dapoxetine hydrochloride and dosulepin hydrochloride in their dosage forms using mercurochrome, Luminescence, 2018, 33(8), 1306-1313.

$7 \mathrm{~L}$. Li, et al., Isolation and structural elucidation of Dapoxetine as an adulterant in a health supplement used for sexual performance enhancement, J. Pharm. Biomed. Anal., 2009, 50(5), 724-728.

8 K. B. Liew and K. K. Peh, Stability indicating HPLC-UV method for determination of Dapoxetine $\mathrm{HCl}$ in pharmaceutical product, Acta Pol. Pharm., 2014, 71(3), 393400.

9 K. B. Liew and K. K. Peh, Stability indicating HPLC method for simultaneous quantification of sildenafil citrate and Dapoxetine hydrochloride in pharmaceutical products, Pak. J. Pharm. Sci., 2018, 31(6), 2515-2522.

10 I. A. Naguib and F. F. Abdallah, Ultraviolet cutoff area and predictive ability of partial least squares regression method: a pharmaceutical case study, Spectrochim. Acta Mol. Biomol. Spectrosc., 2020, 231, 118116.

11 A. M. Abdel-Raoof, et al., D-optimal design as a useful tool response surface methodology for the optimization of signals from synchronous fluorescence prior to simultaneous determination of avanafil and tadalafil, Spectrochim. Acta Mol. Biomol. Spectrosc., 2020, 235, 118313.

$12 \mathrm{H}$. Maha, et al., A novel liquid chromatographic method with fluorescence detection for quantitation of tadalafil and Dapoxetine hydrochloride in pharmaceutical dosage form and human plasma, Se Pu, 2015, 33(7), 765-770.

13 T. A. Mohamed and S. A. Atty, Native and synchronous fluorescence spectroscopy for determination of avanafil in presence of its co-formulated drug (Dapoxetine hydrochloride): application to pharmaceutical product, biological fluid and content uniformity, Spectrochim. Acta Mol. Biomol. Spectrosc., 2020, 229, 117898.

14 A. A. Abu-Hassan, R. Ali and S. M. Derayea, One-pot micellar augmented native fluorescence for facile fluorimetric assay of Dapoxetine hydrochloride in biological plasma and tablets, Spectrochim. Acta Mol. Biomol. Spectrosc., 2020, 239, 118512.

15 T. A. Ahmed, et al., Two-Step Optimization to develop a transdermal film loaded with Dapoxetine nanoparticles: a promising technique to improve drug skin permeation, Dose Response, 2020, 18(2), 1559325820923859.

16 C. L. Hamilton and J. D. Cornpropst, Determination of Dapoxetine, an investigational agent with the potential for treating depression, and its mono- and di-desmethyl metabolites in human plasma using column-switching high-performance liquid chromatography, J. Chromatogr., 1993, 612(2), 253-261.

17 H. Harnisch and G. K. E. Scriba, Capillary electrophoresis method for the determination of (R)-dapoxetine, (3S)-3(dimethylamino)-3-phenyl-1-propanol, (S)-3-amino-3phenyl-1-propanol and 1-naphthol as impurities of Dapoxetine hydrochloride, J. Pharm. Biomed. Anal., 2019, 162, 257-263.

18 B. H. Anwar, et al., Linear support vector regression and partial least-squares for determination of Dapoxetine hydrochloride and Tadalafil in binary pharmaceutical mixtures, J. AOAC Int., 2020, 103(1), 132-139.

19 M. M. Baker, et al., High-performance liquid chromatography with diode array detection method for the simultaneous determination of seven selected phosphodiesterase-5 inhibitors and serotonin reuptake inhibitors used as male sexual enhancers, J. Sep. Sci., 2016, 39(9), 1656-1665. 
20 G. Toth, et al., Liquid chromatographic method for the simultaneous determination of achiral and chiral impurities of dapoxetine in approved and counterfeit products, J. Chromatogr., A, 2020, 1626, 461388.

21 N. O. Can, Development of validated and stability-Indicating LC-DAD and LC-MS/MS methods for determination of Avanafil in pharmaceutical preparations and Identification of a novel degradation product by LCMS-IT-TOF, Molecules, 2018, 23(7), 1771.

22 J. Jung, et al., Tolerability and pharmacokinetics of avanafil, a phosphodiesterase type 5 inhibitor: a single- and multipledose, double-blind, randomized, placebo-controlled, doseescalation study in healthy Korean male volunteers, Clin. Therapeut., 2010, 32(6), 1178-1187.

23 E. Ozturk Er, B. Ozbek and S. Bakirdere, Accurate and sensitive determination of Sildenafil, Tadalafil, Vardenafil, and Avanafil in illicit erectile dysfunction medications and human urine by LC with quadrupole-TOF-MS/MS and their behaviors in simulated gastric conditions, J. Sep. Sci., 2019, 42(2), 475-483.

24 T. Y. Hsueh, et al., Herb-drug interaction of epimedium extract on the pharmacokinetic of Dapoxetine in rats, $J$. Chromatogr., B, 2016, 1014, 64-69.

25 T. K. Kim, et al., Determination of Dapoxetine in rat plasma by ultra-performance liquid chromatography-tandem mass spectrometry, J. Chromatogr., B, 2013, 926, 42-46.

26 R. Said, B. Arafat and T. Arafat, High performance liquid chromatography - mass spectrometric bioanalytical method for the determination of dapoxetine in human plasma: application for bioequivalence study, $J$. Chromatogr., B, 2020, 1149, 122154.

$27 \mathrm{~K}$. Yan, et al., Bioequivalence analysis of 2 Dapoxetine hydrochloride formulations in healthy chinese male volunteers under fed and fasting conditions: a randomized, open-label, 2-sequence, 2-period, 2-way crossover study, Clin. Pharmacol. Drug Dev., 2021, 10(4), 384-392.

28 W. M. Zhang, et al., Development and validation of a sensitive UPLC-MS/MS method for the simultaneous determination of dapoxetine and its two metabolites in human plasma, J. Pharm. Biomed. Anal., 2016, 119, 45-49.

29 C.-C. Liang, et al., Measurement and pharmacokinetic study of tetramethylpyrazine in rat blood and its regional brain tissue by high-performance liquid chromatography, $J$. Chromatogr., B, 1999, 724, 303-309.

30 National Center for Biotechnology Information, https:// pubchem.ncbi.nlm.nih.gov/compound/ Tadalafil\#section $=$ Chemical-and-Physical-Properties, $\mathrm{CID}=110635,2021$.
31 National Center for Biotechnology Information, https:// pubchem.ncbi.nlm.nih.gov/compound/

Dapoxetine\#section $=$ Chemical-and-Physical-Properties, $\mathrm{CID}=71353,2021$.

32 National Center for Biotechnology Information, https:// pubchem.ncbi.nlm.nih.gov/compound/

Avanafil\#section=Chemical-and-Physical-Properties, $\mathrm{CID}=9869929,2021$.

33 M. S. Attia, A. O. Youssef and A. A. Essawy, A novel method for tyrosine assessment in vitro by using fluorescence enhancement of the ion-pair tyrosine-neutral red dye photo probe, Anal. Methods, 2012, 4(8), 2323-2328.

34 M. S. Attia and N. S. AlRadadi, Progress of pancreatitis disease biomarker alpha amylase enzyme by new nano optical sensor, Biosens. Bioelectron., 2016, 86, 413-419.

35 M. S. Attia and N. S. AlRadadi, Nano optical sensor binuclear Pt-2-pyrazinecarboxylic acid -bipyridine for enhancement of the efficiency of 3-nitrotyrosine biomarker for early diagnosis of liver cirrhosis with minimal hepatic encephalopathy, Biosens. Bioelectron., 2016, 86, 406-412.

36 E. Hamed, M. S. Attia and K. Bassiouny, Synthesis, Spectroscopic and Thermal Characterization of Copper(II) and Iron(III) Complexes of Folic Acid and Their Absorption Efficiency in the Blood, Bioinorg. Chem. Appl., 2009, 1-6.

37 M. S. Attia, W. H. Mahmoud, A. O. Youssef and M. S. Mostafa, Cilostazol determination by the enhancement of the green emission of $\mathrm{Tb}^{3+}$ optical sensor, J. Fluoresc., 2011, 21, 2229-2235.

38 M. S. Attia, M. N. Ramsis, L. H. Khalil and S. G. Hashem, Spectrofluorimetric assessment of chlorzoxazone and Ibuprofen in pharmaceutical formulations by using Eutetracycline $\mathrm{HCl}$ optical sensor doped in sol-gel matrix, $J$. Fluoresc., 2012, 22, 779-788.

39 M. S. Attia, Nano optical probe samarium tetracycline complex for early diagnosis of histidinemia in new born children, Biosens. Bioelectron., 2017, 94, 81-86.

40 M. S. Attia, M. M. H. Khalil, M. S. A. Abdel, Y. A. Alekseenko and B. Lukyanov, Effect of complexation with lanthanide metal ions on the photochromism of (1,3,3-trimethyl-5'hydroxy-6'-formyl-indoline-spiro2, $2^{\prime}$-[2h]) in different media, Int. J. Photoenergy, 2006, 2006, 42846.

41 M. S. Attia, A. O. Youssef, Z. A. Khan and M. N. Abou-Omar, Alpha fetoprotein assessment by using a nano optical sensor thin film binuclear Pt-2-aminobenzimidazole-bipyridine for early diagnosis of liver cancer, Talanta, 2018, 186, 36-43.

42 M. S. Attia, K. Ali, M. El-Kemary and W. M. Darwish, Phthalocyanine-doped polystyrene fluorescent nanocomposite as a highly selective biosensor for quantitative determination of cancer antigen 125, Talanta, 2019, 201, 185-193. 